\title{
Platelet Level as a New Prognostic Factor for Idiopathic Pulmonary Arterial Hypertension in the Era of Combination Therapy
}

\author{
Hiroki Taguchi, MD; Masaharu Kataoka, MD; Ryoji Yanagisawa, MD; Takashi Kawakami, MD; \\ Yuichi Tamura, MD; Keiichi Fukuda, MD; Hideaki Yoshino, MD; Toru Satoh, MD
}

\begin{abstract}
Background: The recent development of various effective drugs, such as epoprostenol, sildenafil, and bosentan, has improved the prognosis for patients with idiopathic pulmonary arterial hypertension (IPAH). This study sought to determine survival rates and to identify predictive prognostic factors in patients with IPAH in the current era of combination therapy with new and more effective vasodilators.
\end{abstract}

\begin{abstract}
Methods and Results: In 65 consecutive IPAH patients treated from 2004 to 2009, hemodynamic parameters were significantly improved and brain natriuretic peptide was significantly decreased by combination therapy (observation period: $35 \pm 18$ months). The Kaplan-Meier survival curves were determined, and 22 prognostic variables, including 9 hemodynamic variables and 6 biomarkers, were evaluated to obtain the best variables. The 1-year and 3-year survival rates were $98 \%$ and $86 \%$, respectively. Only the platelet level was correlated with death $(P<0.05)$, and the platelet level was significantly correlated with mean pulmonary arterial pressure $(P<0.01)$. Patients with a lower platelet level $\left(<20 \times 10^{4} / \mu \mathrm{l}\right.$ (median value)) before treatment had a higher mortality rate compared to the other patients (78\% vs. $95 \%$ for 3 -year survival, $\mathrm{P}<0.01$ ).
\end{abstract}

Conclusions: Combination therapy contributed to an improvement in the prognosis of IPAH patients. Platelet level is a significant prognostic predictor in this new treatment era. (Circ $J$ 2012; 76: 1494-1500)

Key Words: Combination therapy; Idiopathic pulmonary arterial hypertension; Platelet; Prognostic factor; Survival

$\mathbf{P}$ ulmonary arterial hypertension (PAH) is a relatively rare condition, often accompanied by a poor outcome due to right heart failure resulting from progressive pulmonary hypertension. A 1991 report cited the median survival period of patients with idiopathic PAH (IPAH) as 2.8 years, with 1-year, 3-year, and 5-year survival rates of $68 \%, 48 \%$, and $34 \%$, respectively. ${ }^{1}$ However, the recent development of various effective drugs, such as prostaglandins, endothelin receptor blockers, and phosphodiesterase inhibitors, has improved the prognosis of such patients. Notably, epoprostenol (prostaglandin) and bosentan (endothelin receptor antagonist) have markedly improved the survival rate among patients with IPAH. ${ }^{2,3}$ Furthermore, sildenafil (phosphodiesterase inhibitor) has improved the exercise capacity, functional class, and hemodynamics of patients with PAH. ${ }^{4}$ Epoprostenol started to be used in Japan in 1999, bosentan in 2006, and sildenafil in 2002, on an off-label basis. Several recent studies have confirmed the improved survival of patients with PAH treated by such mod- ern medical management. ${ }^{5-9}$

Predictive prognostic markers of IPAH warrant investigation because some reports have indicated that better treatment results can be achieved by starting affirmative therapies before the PAH begins to worsen. ${ }^{10,11}$ Thus, therapies should be discussed with prognostic factors taken into account. According to reports published during the 1990s (the era of conventional treatment), the New York Heart Association functional class ${ }^{12}$ and hemodynamic variables such as the mean pulmonary arterial pressure (mPA), cardiac output (CO), and the mean right atrial pressure (mRA) were correlated with the prognosis of IPAH patients, ${ }^{1,13}$ as well as heart rate, exercise tolerance measures including the 6-minute-walk distance (6MWD), and echocardiographic predictors such as pericardial effusion. ${ }^{14-16}$ Furthermore, the levels of uric acid (UA), brain natriuretic peptide (BNP), and von Willebrand factor antigen were each correlated with the prognosis in IPAH patients, ${ }^{17-19}$ implicating them as potential biomarkers. Most of these results were reported before the current

Received October 30, 2011; revised manuscript received February 10, 2012; accepted February 12, 2012; released online March 16 , 2012 Time for primary review: 21 days

Division of Cardiology, Department of Medicine, Kyorin University School of Medicine, Tokyo (H.T., M.K., R.Y., H.Y., T.S.); Division of Cardiology, Department of Medicine, Keio University School of Medicine, Tokyo (M.K., T.K., Y.T., K.F.), Japan

The first two authors contributed equally to this work (H.T., M.K.).

Mailing address: Toru Satoh, MD, Division of Cardiology, Department of Medicine, Kyorin University School of Medicine, 6-20-2

Shinkawa, Mitaka, Tokyo 181-8611, Japan. E-mail: tsatoh@ks.kyorin-u.ac.jp

ISSN-1346-9843 doi:10.1253/circj.CJ-11-1223

All rights are reserved to the Japanese Circulation Society. For permissions, please e-mail: cj@j-circ.or.jp 


\begin{tabular}{|c|c|c|c|c|}
\hline & $\begin{array}{l}\text { Total patient } \\
\text { group }(n=65)\end{array}$ & $\begin{array}{l}\text { Low platelet } \\
\text { group }(n=33)\end{array}$ & $\begin{array}{l}\text { High platelet } \\
\text { group }(n=32)\end{array}$ & P value ${ }^{\star *}$ \\
\hline Average number of used drugs & $1.94 \pm 0.86$ & $2.00 \pm 0.83$ & $1.88 \pm 0.91$ & 0.564 \\
\hline \multicolumn{5}{|l|}{$\begin{array}{l}\text { Breakdown of combination therapy } \\
\text { (number of patients) }\end{array}$} \\
\hline 1 Drug & 25 & 10 & 15 & 0.170 \\
\hline Epoprostenol & 9 & 6 & 3 & 0.304 \\
\hline Bosentan & 6 & 1 & 5 & 0.080 \\
\hline Sildenafil & 10 & 3 & 7 & 0.153 \\
\hline 2 Drugs & 18 & 12 & 6 & 0.113 \\
\hline Epoprostenol and bosentan & 3 & 1 & 2 & 0.964 \\
\hline Epoprostenol and sildenafil & 3 & 3 & 0 & 0.081 \\
\hline Bosentan and sildenafil & 12 & 8 & 4 & 0.223 \\
\hline 3 Drugs & 22 & 11 & 11 & 0.929 \\
\hline Sum number of epoprostenol & 37 & 21 & 16 & 0.267 \\
\hline Period of epoprostenol, months & $54 \pm 29$ & $55 \pm 30$ & $53 \pm 29$ & 0.833 \\
\hline Maximum dose of epoprostenol, $\mathrm{ng} \cdot \mathrm{kg}^{-1} \cdot \mathrm{min}^{-1}$ & $49 \pm 31$ & $53 \pm 39$ & $43 \pm 12$ & 0.462 \\
\hline Sum number of bosentan & 43 & 21 & 22 & 0.663 \\
\hline Period of bosentan, months & $34 \pm 17$ & $36 \pm 18$ & $33 \pm 16$ & 0.510 \\
\hline Sum number of sildenafil & 47 & 25 & 22 & 0.528 \\
\hline Period of sildenafil, months & $20 \pm 9.3$ & $20 \pm 7.2$ & $19 \pm 11$ & 0.814 \\
\hline
\end{tabular}

${ }^{\star *}$ Comparison between low platelet group and high platelet group.

combined use of effective medical treatments, thus more relevant prognostic factors for PAH need to be evaluated.

This study therefore sought to: (1) estimate the current survival rate of patients with IPAH in the modern era of combination therapy using epoprostenol, bosentan, and sildenafil; and (2) reconsider novel favorable prognostic predictors, focusing on non-invasive and less-often evaluated prognostic variables.

\section{Methods}

\section{Study Subjects}

Sixty-five consecutive patients with IPAH who underwent an initial right cardiac catheterization to diagnose and assess its severity from July 2004 to December 2009 were enrolled in this study. Patients were diagnosed as having IPAH after ruling out connective tissue disease, congenital heart defect, portal hypertension, human immunodeficiency, pulmonary disease, pulmonary thromboembolism, left heart abnormality, and other systemic diseases. The ethics committee at the relevant institutions approved the study protocol. All the patients provided written informed consent before enrollment.

\section{Evaluation of Prognosis}

The survival period was calculated as the number of months from the first catheterization to December 2009 (the end of the follow up in this study) or to patient death if that occurred first. Survival period is usually calculated from the day of diagnosis; however, this date was close to that of the first catheterization, and the aim of this study was to select the most suitable prognostic variables. Consequently, the catheterization day was used as the start date for calculating the survival period in this study. Patient survival was evaluated using a Kaplan-Meier survival curve, as explained in the statistical analysis section below.

\section{Prognostic Variables}

Twenty-two variables were chosen to analyze prognosis in this study. The prognostic variables comprised 9 hemodynamic variables, 6 serological variables, and 3 blood gas variables along with the cardiothoracic ratio, heart rate, age, and 6MWD. Among the variables analyzed, mRA, mPA, CO, UA, BNP, heart rate, and 6MWD were included because they have been correlated with mortality among patients with PAH.1,10,13,17,18

The following parameters were measured when the patients underwent right heart catheterization for the first time: mRA, A wave level of the right atrial pressure, right ventricular end diastolic pressure, pulmonary arterial systolic pressure, pulmonary arterial diastolic pressure, $\mathrm{mPA}$, and pulmonary capillary wedge pressure (PCWP). The CO was calculated using the Fick method, and pulmonary vascular resistance (PVR) was calculated by subtracting PCWP from mPA, and then dividing by the pulmonary blood flow. 'Wood unit' was adopted as the unit of PVR. Blood gas measurements were performed to obtain the partial pressure of arterial oxygen, the partial pressure of arterial carbon dioxide, and the venous oxygen saturation level during catheterization.

Blood sampling was also performed to obtain the hemoglobin, platelet, total bilirubin, UA, BNP, and ALP levels. These parameters were examined at the PAH outpatient clinic at the time of each patient's first visit.

\section{Combination Therapy for IPAH}

After the baseline examinations, the treatment most suitable for each patient was instituted based on the algorithm proposed at the world symposium in Venice, Italy, in 2003 and revised at Dana Point, USA, in 2008..$^{20,21}$

The maximum dose of bosentan was $125 \mathrm{mg}$ b.i.d., while that of sildenafil was $20 \mathrm{mg}$ t.i.d., as long as all adverse effects were tolerable. If epoprostenol was added, the dosage was started at $1 \mathrm{ng} \cdot \mathrm{min}^{-1} \cdot \mathrm{kg}^{-1}$ and increased gradually to a dose of approximately 30ng $\cdot \mathrm{min}^{-1} \cdot \mathrm{kg}^{-1}$ at 6 months and $50 \mathrm{ng} \cdot \mathrm{min}^{-1} \cdot \mathrm{kg}^{-1}$ at 1 year. When patients were non-responsive to 1 drug within 6 


\begin{tabular}{|c|c|c|c|}
\hline & Baseline & $\begin{array}{c}\text { After } \\
\text { combination } \\
\text { therapy }\end{array}$ & $P$ value \\
\hline $\mathrm{mRA}, \mathrm{mmHg}$ & $7.6 \pm 4.7$ & $6.4 \pm 4.5$ & 0.166 \\
\hline $\mathrm{mPA}, \mathrm{mmHg}$ & $55 \pm 14$ & $46 \pm 14$ & $0.003^{*}$ \\
\hline PVR, wood unit & $15 \pm 7.5$ & $12 \pm 8.5$ & $0.011^{*}$ \\
\hline $\mathrm{CO}, \mathrm{L} / \mathrm{min}$ & $3.6 \pm 1.3$ & $4.2 \pm 1.7$ & $0.006^{*}$ \\
\hline $\mathrm{BNP}, \mathrm{pg} / \mathrm{ml}$ & $248 \pm 327$ & $46 \pm 59$ & 0.085 \\
\hline 6MWD, m & $342 \pm 121$ & $373 \pm 122$ & 0.329 \\
\hline
\end{tabular}

${ }^{*} \mathrm{P}<0.05$

$\mathrm{mRA}$, mean right atrial pressure; $\mathrm{mPA}$, mean pulmonary arterial pressure; PVR, pulmonary vascular resistance; $\mathrm{CO}$, cardiac output; $\mathrm{BNP}$, brain natriuretic peptide; 6MWD, six-minute-walk distance.

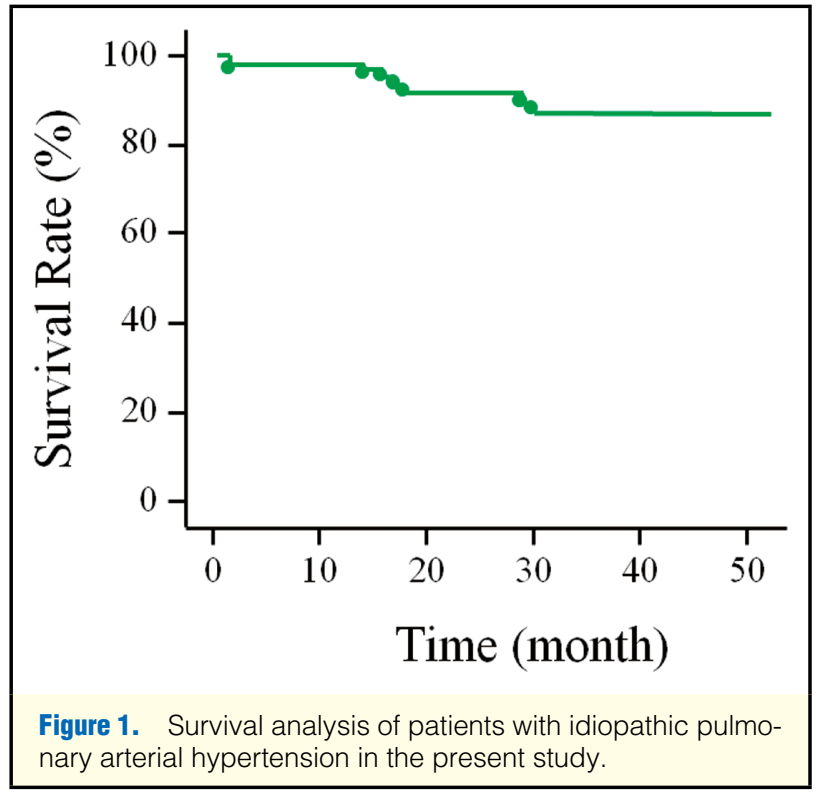

\begin{tabular}{|c|c|c|c|c|}
\hline & $\begin{array}{c}\text { Total patients } \\
(n=65)\end{array}$ & $\begin{array}{l}\text { Low platelet } \\
\text { Group }(n=33)\end{array}$ & $\begin{array}{l}\text { High platelet } \\
\text { Group }(n=32)\end{array}$ & P value ${ }^{\star *}$ \\
\hline Age, years & $40 \pm 13$ & $41 \pm 13$ & $40 \pm 13$ & 0.765 \\
\hline Sex (male, \%) & $14(22)$ & $9(27)$ & $5(16)$ & 0.253 \\
\hline \multicolumn{5}{|l|}{ NYHA FC, number (\%) } \\
\hline 1 or 2 & $8(12)$ & $3(9)$ & $5(16)$ & 0.423 \\
\hline 3 & $57(88)$ & $30(91)$ & $27(84)$ & 0.423 \\
\hline 4 & $0(0)$ & $0(0)$ & $0(0)$ & - \\
\hline Heart rate, beats/min & $82 \pm 22$ & $82 \pm 16$ & $83 \pm 28$ & 0.972 \\
\hline $\mathrm{mRA}, \mathrm{mmHg}$ & $7.6 \pm 4.7$ & $7.7 \pm 4.3$ & $7.5 \pm 5.2$ & 0.990 \\
\hline A wave of $\mathrm{RA}, \mathrm{mmHg}$ & $13 \pm 5.0$ & $13 \pm 4.8$ & $13 \pm 5.3$ & 0.899 \\
\hline RVEDP, $\mathrm{mmHg}$ & $13 \pm 5.6$ & $13 \pm 5.0$ & $13 \pm 6.3$ & 0.604 \\
\hline $\mathrm{PAs}, \mathrm{mmHg}$ & $87 \pm 21$ & $91 \pm 20$ & $82 \pm 21$ & 0.074 \\
\hline PAd, $\mathrm{mmHg}$ & $34 \pm 11$ & $38 \pm 12$ & $31 \pm 8.8$ & $0.013^{*}$ \\
\hline $\mathrm{mPA}, \mathrm{mmHg}$ & $55 \pm 14$ & $59 \pm 14$ & $51 \pm 13$ & $0.027^{*}$ \\
\hline PCWP, mmHg & $7.6 \pm 3.4$ & $7.8 \pm 2.9$ & $7.4 \pm 3.8$ & 0.561 \\
\hline PVR, wood unit & $15 \pm 7.5$ & $17 \pm 8.2$ & $14 \pm 6.6$ & 0.388 \\
\hline $\mathrm{CO}, \mathrm{L} / \mathrm{min}$ & $3.6 \pm 1.3$ & $3.6 \pm 1.5$ & $3.5 \pm 1.2$ & 0.697 \\
\hline Hemoglobin, g/dl & $14.2 \pm 2.4$ & $14.6 \pm 2.6$ & $13.8 \pm 2.2$ & 0.189 \\
\hline Total bilirubin, $\mathrm{mg} / \mathrm{dl}$ & $1.1 \pm 0.54$ & $1.2 \pm 0.5$ & $1.1 \pm 0.6$ & 0.267 \\
\hline UA, mg/dl & $6.6 \pm 1.8$ & $6.8 \pm 2.0$ & $6.4 \pm 1.6$ & 0.370 \\
\hline $\mathrm{BNP}, \mathrm{pg} / \mathrm{ml}$ & $248 \pm 327$ & $272 \pm 321$ & $223 \pm 337$ & 0.587 \\
\hline ALP, IU/L & $236 \pm 72$ & $243 \pm 81$ & $228 \pm 59$ & 0.372 \\
\hline $\mathrm{PaO}_{2}$, Torr & $72 \pm 11$ & $73 \pm 12$ & $70 \pm 11$ & 0.271 \\
\hline $\mathrm{PaCO}_{2}$, Torr & $35 \pm 4.6$ & $35 \pm 3.8$ & $36 \pm 5.3$ & 0.364 \\
\hline $\mathrm{SvO}_{2}, \%$ & $65 \pm 9.1$ & $65 \pm 9.1$ & $65 \pm 9.3$ & 0.922 \\
\hline CTR, \% & $54 \pm 7.0$ & $53 \pm 6.8$ & $56 \pm 7.2$ & 0.320 \\
\hline 6MWD, m & $342 \pm 121$ & $323 \pm 103$ & $366 \pm 143$ & 0.432 \\
\hline
\end{tabular}

${ }^{*} \mathrm{P}<0.05$. ${ }^{* *}$ Comparison between low platelet group and high platelet group.

NYHA FC, New York Heart Association functional class; A wave of RA, A wave level of right atrial pressure; RVEDP, right ventricular end diastolic pressure; PAs, pulmonary arterial systolic pressure; PAd, pulmonary arterial diastolic pressure; PCWP, pulmonary capillary wedge pressure; UA, uric acid; ALP, alkaline phosphatase; $\mathrm{PaO}_{2}$, partial pressure of arterial oxygen; $\mathrm{PaCO}_{2}$, partial pressure of arterial carbon dioxide; $\mathrm{SvO}_{2}$, venous oxygen saturation; CTR, cardiothoracic ratio. Other abbreviations are defined in Table 2. 
months and/or their condition became aggravated, another drug regimen was added 1 at a time.

Epoprostenol began to be used in 1999, sildenafil began to be used on an off-label basis in 2002, and bosentan began to be used in 2005 in Japan. Since this study was started in 2004, most of the patients had access to treatment with epoprostenol, bosentan, and sildenafil.

\section{Statistical Analysis}

Hemodynamic and serological parameters were compared for patients before and after combination therapy by using a Student's paired t-test. Kaplan-Meier survival curves were used to investigate the survival rate of all enrolled patients with IPAH in the present study. Variables and the periods of each drug administration were compared between the 2 groups using a Student's unpaired t-test. Twenty prognostic variables observed at the time of the first diagnosis were evaluated using the Cox proportional hazards test. The most significant variables correlating with mortality were chosen, and correlation coefficients between significant non-invasive prognostic variables and hemodynamic variables were calculated by linear regression analysis. The proportion of each drug administration, patient sex, and baseline New York Heart Association (NYHA) functional class were compared by using the chi-square test between the 2 groups. The patients were then divided into 2 groups according to the median value of certain significant prognostic variables, and Kaplan-Meier survival curves were applied to compare mortality rates in patients with higher and lower platelet numbers. All data are expressed as mean \pm standard deviation. A value of $\mathrm{P}<0.05$ was considered statistically significant.

\section{Results}

\section{Changes in Hemodynamic and Serological Parameters Following Combination Therapy}

Table 1 details the distribution of each medication and pattern classification of the combination therapy. Epoprostenol was administrated in 37 cases, bosentan in 43 cases, and sildenafil in 47 cases, with administration periods of $54 \pm 29,34 \pm 17$, and $20 \pm 9.3$ months, respectively. Each patient received $1.94 \pm 0.86$ medications; 18 patients received 2 different drugs and 20 patients received 3 drugs. Table 2 lists the changes in hemodynamic and serological parameters following combination therapy using epoprostenol, bosentan, and sildenafil. The observation period was $37 \pm 17$ months. Hemodynamic parameters such as mPA, PVR, and CO were significantly improved, and BNP was significantly decreased by the combination therapy.

\section{Survival Analysis}

Nine patients died during the observation period, because of right heart failure exacerbation. No patients died due to noncardiac events such as infection and cancer. Figure 1 shows the survival curves of all the enrolled patients with IPAH in the present study. The 1-year and 3-year survival rates were $98 \%$ and $86 \%$, respectively.

\section{Significant Prognostic Variables}

We then analyzed the prognostic variables in patients with IPAH. Baseline mPA, mRA, and PVR values were $55 \pm 14 \mathrm{mmHg}$, $7.6 \pm 4.7 \mathrm{mmHg}$, and $15.0 \pm 7.5 \mathrm{Wood}$ units, respectively (Table 3). The Cox proportional hazards test was used to determine whether each prognostic variable was correlated with the death of patients with IPAH. Platelet level was the only parameter correlated with death among the 22 prognostic variables examined (Table 4). Correlation analysis of specific hemodynamic

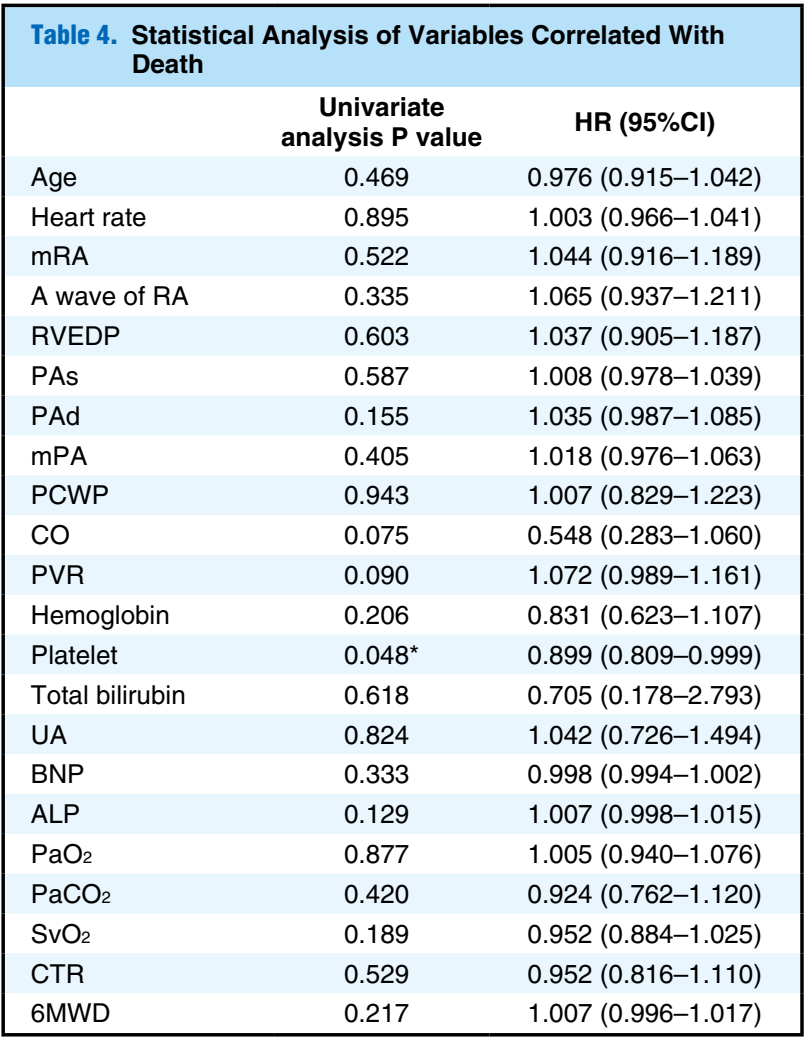

$\mathrm{HR}$, hazard ratio; $\mathrm{Cl}$, confidence interval. Other abbreviations are defined in Tables 2,3.

$$
{ }^{*} \mathrm{P}<0.05 \text {. }
$$

variables with platelet level revealed a significant inverse correlation with the mPA value only (Figure 2). Additionally, there was no significant difference between the platelet levels of the patients who were treated with epoprostenol $(n=37)$ and those of the patients who were not treated with epoprostenol $(\mathrm{n}=28)$ $\left(20 \pm 7.9 \times 10^{4} / \mu \mathrm{l}\right.$ vs. $\left.20 \pm 7.0 \times 10^{4} / \mu \mathrm{l}\right)$.

\section{Survival Analysis According to Platelet Level}

We analyzed survival according to the platelet level among individual patients with IPAH, in whom the median platelet level was $20 \times 10^{4} / \mu 1$. There was no significant difference in observation periods between the high platelet group (platelets $\geq 20 \times 10^{4} / \mu \mathrm{l} ; 34 \pm 17$ months) and the low platelet group (platelets $<20 \times 10^{4} / \mu \mathrm{l} ; 39 \pm 16$ months). The distribution of NYHA functional class, the number of epoprostenol administrations, the period of epoprostenol administration, and the maximum dose of epoprostenol were not significantly different between the groups (Tables 1,3). As shown in Table 3, a significant difference in the baseline mPA level obtained by right heart catheterization was observed between the groups, consistent with a significant correlation between the baseline platelet level and mPA (as shown in Figure 2). However, no significant differences in the baseline serological variables and other hemodynamic variables, such as mRA, PVR, and CO, were observed between the high and low platelet groups.

Kaplan-Meier survival curves drawn according to the median baseline platelet level demonstrated that IPAH patients with a low platelet level had a significantly higher mortality rate than those with a high platelet level (Figure 3). Surprisingly, the 3-year survival rate of IPAH patients in the low platelet group was $78 \%$, while it increased to $95 \%$ in the high 


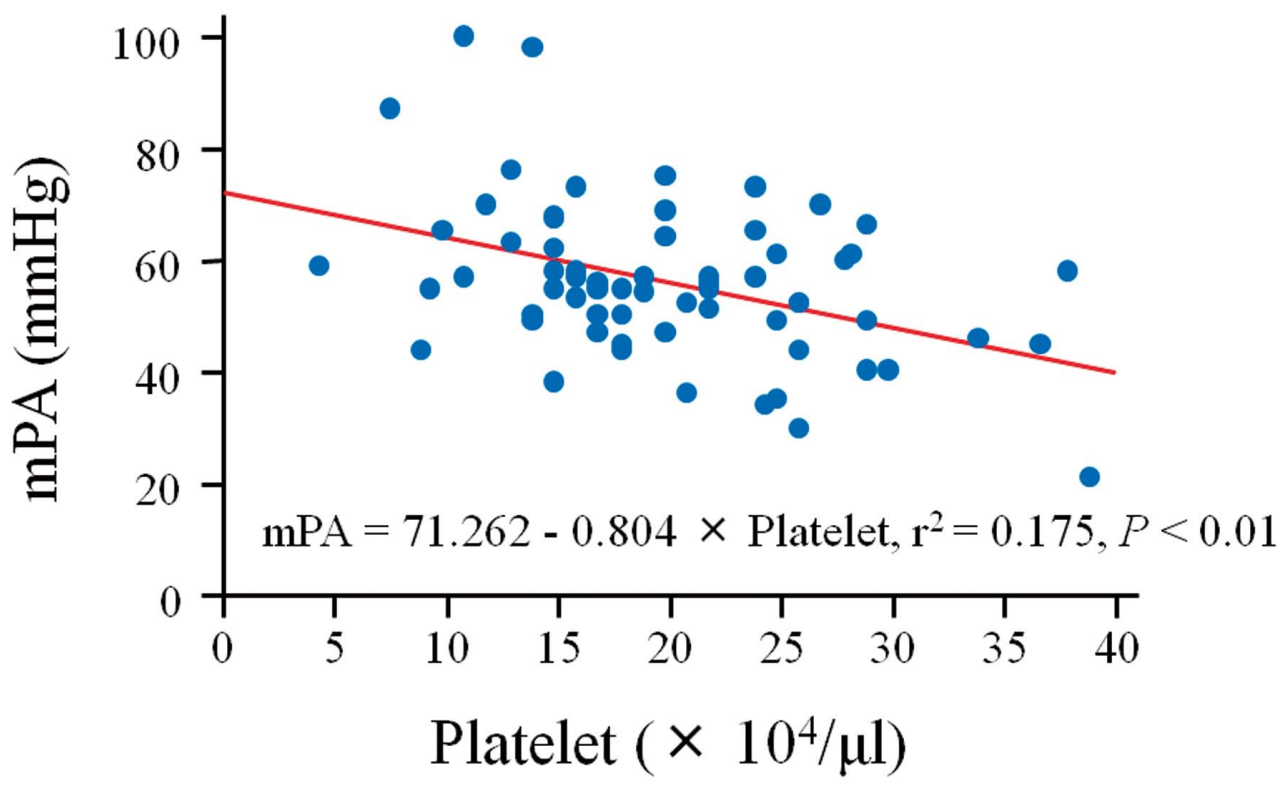

Figure 2. Correlation between mean pulmonary arterial pressure (mPA) and platelet levels in patients with idiopathic pulmonary arterial hypertension. Linear regression analysis revealed a significant relationship between the parameters.

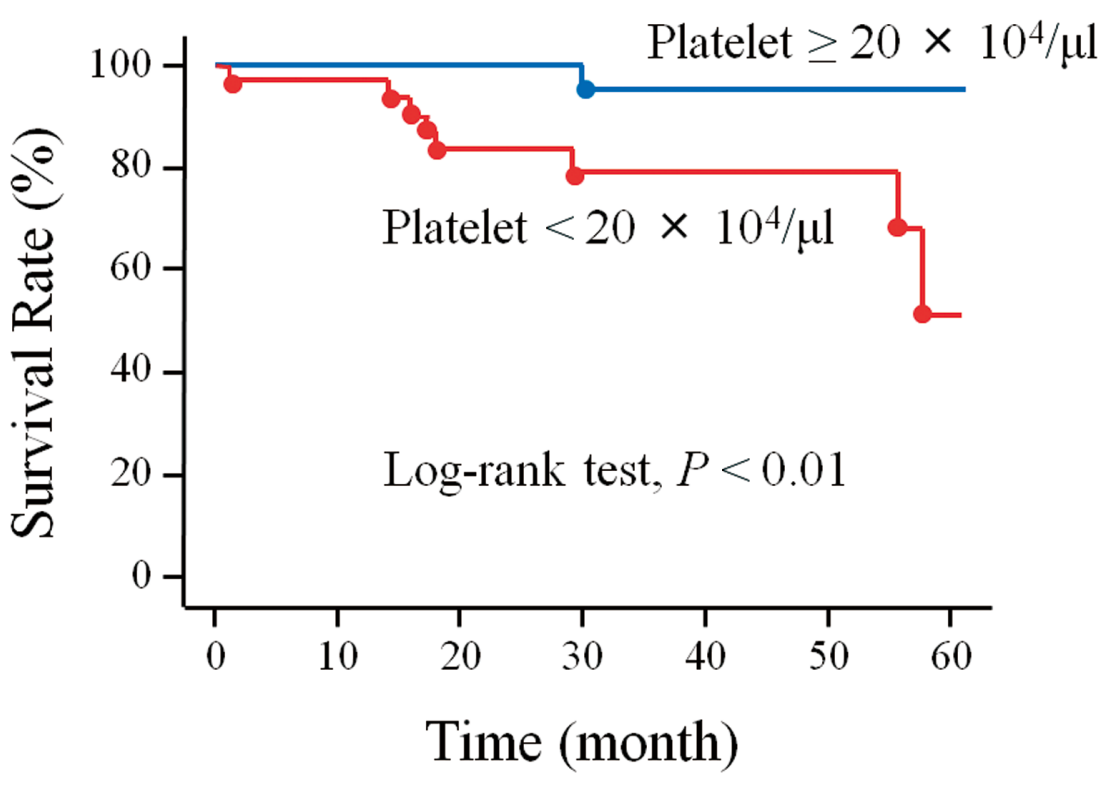

Figure 3. Kaplan-Meier survival curves according to the median platelet level. Patients with low platelet levels (platelet $<20 \times 10^{4} / \mu$ ) (red line) had a significantly lower survival rate than those with high platelet levels (platelet $\geq 20 \times 10^{4} / \mu$ ) (blue line) (log-rank test, $\mathrm{P}<0.01)$.

platelet group.

One patient in the high platelet group died during the observation period compared to 8 patients in the low platelet group. Therefore, the sensitivity of the platelet level for death was $89 \%$ and the specificity was $55 \%$, with the cut-off level at $20 \times 10^{4} / \mu$ l.

\section{Discussion}

\section{Therapeutic Efficacy and Survival in Patients With IPAH Treated With Combination Therapy}

In the present study, hemodynamic parameters such as mPA,
PVR, and CO were significantly improved, and BNP was significantly decreased by combination therapy using epoprostenol, bosentan, and sildenafil, suggesting the clinical therapeutic efficacy of such a therapeutic regimen. Epoprostenol, bosentan, and sildenafil were recently developed as new vasodilators for the treatment of IPAH, resulting in improved health and prognosis in some cases, ${ }^{2-4}$ which is consistent with our results. Together, these findings suggest that the appropriate introduction of new vasodilators in the era of combination therapy could improve the hemodynamics of patient with IPAH more than that with the older conventional therapies. 
In this study, the 1-year and 3-year survival rates of the IPAH patients were $98 \%$ and $86 \%$, respectively. According to a previous report that demonstrated the natural history of IPAH patients enrolled from 1981 to 1985 before the advent of these new therapies, the 1-year, 3-year, and 5-year survival rates reported for IPAH patients were $68 \%, 48 \%$, and $34 \%$, respectively. ${ }^{1}$ A report published in 1999 also cited a median survival period for Japanese patients with IPAH of 3.6 years, with 1-year, 3-year, and 5-year survival rates of 77\%, 44\%, and $23 \%$, respectively. ${ }^{22}$ The survival of PAH patients has clearly been improved since the establishment of epoprostenol therapy. Two studies in 2002 reported 1-year, 3-year, and 5-year survival rates in IPAH patients treated with epoprostenol of $88 \%, 63 \%$, and $47 \%$, respectively, and $85 \%, 63 \%$, and $55 \%$, respectively, 5,7 while a 2005 report cited 1-year and 3-year survival rates of $87 \%$ and $75 \%$, respectively. ${ }^{23}$ Our results thus confirmed a marked improvement in survival rates for IPAH patients compared to those treated in the past, and demonstrated that the combination therapy using epoprostenol, bosentan, and sildenafil directly contributed to a better prognosis in these patients. Recently, several studies have discussed the survival of patients with PAH treated in the modern management era. ${ }^{5-8}$ In 2010, Humbert et $\mathrm{al}^{6}$ reported 1-year and 3-year survival rates of $83 \%$ and $58 \%$, respectively, and a baseline NYHA functional class IV rate of $14 \%$; in our study, this value was $0 \%$. This difference in baseline NYHA functional classes might explain why the survival in our study was relatively better than that in other recent studies.

\section{Platelet Levels and Mortality}

Hemodynamic variables, such as mPA, CO, mRA, and the cardiac index, have been reported to be some of the most powerful prognostic variables among patients with PAH. ${ }^{1,13,24}$ Interestingly, these variables did not correlate with patient survival in the present study. Our results identified only a low platelet level at baseline as a significant factor indicating a poor prognosis in patients with IPAH. Furthermore, there was a significant correlation between the baseline platelet level and the mPA, and those patients who had a platelet level lower than $20 \times 10^{4} / \mu \mathrm{l}$ at baseline had significantly lower survival rates. We did not recognize a statistically significant difference in the NYHA functional severity, the distribution of patients administered epoprostenol the period of epoprostenol administration, and the maximum dose of epoprostenol between the patients with baseline low platelet levels and those with higher levels. Therefore, these findings suggest that platelet levels are correlated with pressure levels of PAH separately from functional severity regardless of whether epoprostenol is used, and that epoprostenol did not influence the improved survival rate in patients with baseline high platelet levels. In contrast, previous reports have associated hemodynamics and epoprostenol with thrombocytopenia in $\mathrm{PAH}$, and epoprostenol is known to reduce platelet counts and suppress platelet aggregation. ${ }^{25,26}$ In the present study, there was no significant difference between the platelet levels of the patients who were treated with epoprostenol and those not receiving epoprostenol. These results suggested that the platelet level is an independent prognostic factor in patients with IPAH, which is independent of epoprostenol treatment.

Generally, the mechanisms of thrombocytopenia include: (1) a reduction in platelet production caused mainly by megakaryocyte hypoplasia or ineffective thrombopoiesis; ${ }^{27,28}$ (2) an increase in platelet destruction as a result of immunological processes, thrombotic microangiopathies, or abnormal vascular surfaces; ${ }^{27-29}$ and (3) an abnormal platelet distribution or pool- ing arising from disorders of the spleen or hypothermia. ${ }^{27,28,30}$ In the present study, there were no significant differences in mRA, BNP, or bilirubin levels, which indicate right heart failure and congestive liver, between the patients with low and high platelet levels. Thus, this study provided no evidence that the thrombocytopenia was due to liver or spleen congestion caused by right heart failure. Further studies are needed to investigate the mechanism of association between thrombocytopenia and the prognosis of IPAH.

\section{Clinical Implications}

Platelet levels can be simply, routinely, and non-invasively measured through venipuncture and blood collection. Platelet levels might thus provide a promising new marker for estimating the prognosis of patients with IPAH in the era of combination therapy. Such measurements will likely contribute to the staging of IPAH patients and might improve treatment further.

\section{Study Limitations}

In this study, the average observation period was $37 \pm 17$ months, which is somewhat short. However, this period was sufficient to evaluate the 3-year outcome. A longer observation period would be needed to determine the 5-year and 10year survival outcomes. The number of patients in the present study was only 65 , but this number was also thought to be sufficient because a Cox proportional hazards test was able to select statistically significant prognostic factors among 22 variables. The number of patients should also be increased to evaluate long-term survival. Thus, a study with a longer observation period and a larger number of patients is needed to confirm our results on an expanded basis. Furthermore, this study is a retrospective study, and the observation period and the treatment regimen of the enrolled patients were individually different. If the platelet level is validated as a prognostic factor of IPAH, the prospective study is desired and the optimum cut-off platelet level should be analyzed.

\section{Conclusions}

The survival rate of patients with IPAH in the current era of combination therapy has improved markedly, and platelet level could provide a useful means of prognostic stratification in this modern context.

\section{Disclosures}

No grants were obtained for this study.

\section{References}

1. D’Alonzo GE, Barst RJ, Ayres SM, Bergofsky EH, Brundage BH, Derte KM, et al. Survival in patients with primary pulmonary hypertension: Results from a national prospective registry. Ann Intern Med 1991; 115: $343-349$.

2. Barst RJ, Rubin LJ, McGoon MD, Caldwell EJ, Long WA, Levy PS. Survival in primary pulmonary hypertension with long-term continuous intravenous prostacyclin. Ann Intern Med 1994; 121: 409415.

3. Provencher S, Sitbon O, Humbert M, Cabrol S, Jaïs X, Simonneau G. Long-term outcome with first-line bosentan therapy in idiopathic pulmonary arterial hypertension. Eur Heart J 2006; 27: 589-595.

4. Galiè N, Ghofrani HA, Torbicki A, Barst RJ, Rubin LJ, Badesch D, et al. Sildenafil citrate therapy for pulmonary arterial hypertension $N$ Engl J Med 2005; 353: 2148-2157.

5. Thenappan T, Shah SJ, Rich S, Tian L, Archer SL, Gomberg-Maitland M. Survival in pulmonary arterial hypertension: A reappraisal of the NIH risk stratification equation. Eur Respir J 2010; 35: 1079-1087.

6. Humbert M, Sitbon O, Chaouat A, Bertocchi M, Habib G, Gressin $\mathrm{V}$, et al. Survival in patients with idiopathic, familial, and anorexi- 
gen-associated pulmonary arterial hypertension in the modern management era. Circulation 2010; 122: 156-163.

7. Benza RL, Miller DP, Gomberg-Maitland M, Frantz RP, Foreman $\mathrm{AJ}$, Coffey CS, et al. Predicting survival in pulmonary arterial hypertension: Insights from the Registry to Evaluate Early and Long-Term Pulmonary Arterial Hypertension Disease Management (REVEAL). Circulation 2010; 122: $164-172$.

8. Humbert M, Sitbon O, Yaïci A, Montani D, O'Callaghan DS, Jaïs X, et al. Survival in incident and prevalent cohorts of patients with pulmonary arterial hypertension. Eur Respir J 2010; 36: 549-555.

9. Fukumoto Y, Shimokawa H. Recent progress in the management of pulmonary hypertension. Circ J 2011; 75: 1801-1810.

10. McLaughlin VV, Shillington A, Rich S. Survival in primary pulmonary hypertension: The impact of epoprostenol therapy. Circulation 2002; 106: $1477-1482$

11. Galiè N, Rubin LJ, Hoeper MM, Jansa P, AI-Hiti H, Meyer GMB, et al. Treatment of patients with mildly symptomatic pulmonary arterial hypertension with bosentan (EARLY study): A double-blind, randomized controlled trial. Lancet 2008; 371: 2093-2100.

12. Sitbon O, Humbert M, Nunes H, Parent F, Garcia G, Hervé P, et al. Long-term intravenous epoprostenol infusion in primary pulmonary hypertension: Prognostic factors and survival. J Am Coll Cardiol 2002; 40: $780-788$

13. Sandoval J, Bauerle O, Palomar A, Gomez A, Martinez-Guerra ML, Beltran M, et al. Survival in primary pulmonary hypertension: Validation of a prognostic equation. Circulation 1994; 89: 1733-1744.

14. Barst RJ, Rubin LJ, Long WA, McGoon MD, Rich S, Badesch DB, et al. A comparison of continuous intravenous epoprostenol (prostacyclin) with conventional therapy for primary pulmonary hypertension: The Primary Pulmonary Hypertension Study Group. N Engl J Med 1996; 334: 296-301.

15. Eysmann SB, Palevsky HI, Reichek N, Hackney K, Douglas PS. Twodimensional and Doppler-echocardiographic and cardiac catheterization correlates of survival in primary pulmonary hypertension. Circulation 1989; 80: $353-360$.

16. Tei C, Dujardin KS, Hodge DO. Doppler echocardiographic index for assessment of global right ventricular function. J Am Soc Echocardiogr 1996; 9: 838-847.

17. Nagaya N, Uematsu M, Satoh T, Kyotani S, Sakamaki F, Nakanishi $\mathrm{N}$, et al. Serum uric acid levels correlate with the severity and the mortality of primary pulmonary hypertension. Am J Respir Crit Care Med 1999; 160: 487-492.

18. Nagaya N, Nishikimi T, Uematsu M, Satoh T, Kyotani S, Sakamaki $\mathrm{F}$, et al. Plasma brain natriuretic peptide as a prognostic indicator in patients with primary pulmonary hypertension. Circulation 2000; 102: 865-870.

19. Lopes AA, Maeda NY, Gonçalves RC, Bydlowski SP. Endothelial cell dysfunction correlates differentially with survival in primary and secondary pulmonary hypertension. Am Heart J 2000; 139: 618-623.

20. Galiè N, Seeger W, Naeije R, Simonneau G, Rubin LJ. Comparative analysis of clinical trials and evidence-based treatment algorithm in pulmonary arterial hypertension. J Am Coll Cardiol 2004; 43(12 Suppl S): $81 \mathrm{~S}-88 \mathrm{~S}$.

21. Barst RJ, Gibbs JSR, Ghofrani HA, Hoeper MM, McLaughlin VV, Rubin LJ, et al. Updated evidence-based treatment algorithm in pulmonary arterial hypertension. J Am Coll Cardiol 2009; 54(1 Suppl): S78-S84.

22. Kunieda T, Nakanishi N, Satoh T, Kyotani S, Okano Y, Nagaya N. Prognoses of primary pulmonary hypertension and chronic major vessel thromboembolic pulmonary hypertension determined from cumulative survival curves. Intern Med 1999; 38: 543-546.

23. Kawut SM, Horn EM, Berekashvili KK, Garofano RP, Goldsmith RL, Widlitz AC, et al. New predictors of outcome in idiopathic pulmonary arterial hypertension. Am J Cardiol 2005; 95: 199-203.

24. Miura Y, Fukumoto Y, Sugimura K, Oikawa M, Nakano M, Tatebe $\mathrm{S}$, et al. Identification of new prognostic factors of pulmonary hypertension. Circ J 2010; 74: 1965-1971.

25. Chin KM, Channick RN, de Lemos JA, Kim NH, Torres F, Rubin LJ. Hemodynamics and epoprostenol use are associated with thrombocytopenia in pulmonary arterial hypertension. Chest 2009; 135: $130-136$.

26. Ogawa A, Matsubara H, Fujio H, Miyaji K, Nakamura K, Morita H, et al. Risk of alveolar hemorrhage in patients with primary pulmonary hypertension: Anticoagulation and epoprostenol therapy. Circ J 2005; 69: 216-220.

27. Rodgers GM. Thrombocytopenia, pathophysiology and classification. In: Greer JP, Foerster J, Rodgers GM, Paraskevas F, Glader B, Arber DA, et al, editors. Wintrobe's Clinical Hematology. Philadelphia, PA: Wolters Kluwer Health/Lippincott Williams \& Wilkins, 2009; 12891291.

28. Agarwal N, Rodgers GM. Miscellaneous causes of thrombocytopenia. In: Greer JP, Foerster J, Rodgers GM, Paraskevas F, Glader B, Arber DA, et al, editors. Wintrobe's Clinical Hematology. Philadelphia, PA: Wolters Kluwer Health/Lippincott Williams \& Wilkins, 2009; 1326 1334.

29. Thienelt CD, Calverley DC. Thrombocytopenia caused by immunologic platelet destruction. In: Greer JP, Foerster J, Rodgers GM, Paraskevas F, Glader B, Arber DA, Means RT, editors. Wintrobe's Clinical Hematology. Philadelphia, PA: Wolters Kluwer Health/Lippincott Williams \& Wilkins, 2009; $1292-1313$

30. Henry PH, Longo DL. Enlargement of lymph nodes and spleen. In: Fauci AS, Braunwald E, Kasper DL, Hauser SL, Longo DL, Jameson JL, et al, editors. Harrison's Principles of internal medicine. New York: McGraw-Hill Medical, 2008; 370-375. 